\title{
Effects of DDT and Dicofol on Life Table Demography of the Freshwater Rotifer Brachionus calyciflorus Pallas
}

\author{
Xiao-Ping Xu${ }^{*}$, Yi-Long $\mathrm{Xi}^{2}$, Xing-Ming Wang ${ }^{3}$ \\ ${ }^{1}$ College of Civil Engineering and Architecture, Anhui Polytechnic University, Wuhu, China \\ ${ }^{2}$ Collaborative Innovation Center of Recovery and Reconstruction of Degraded Ecosystems in Wanjiang City Belt, \\ College of Life Sciences, Anhui Normal University, Wuhu, China \\ ${ }^{3}$ School of Earth and Environment, Anhui University of Science and Technology, Huainan, China
}

Received: 3 February 2019

Accepted: 24 April 2019

\begin{abstract}
DDT and dicofol are two typical persistent organic pollutants and raise great concerns around the world because of their resistance to decay in the environment. Little is known regarding their effects on life table variables of rotifers, including age at first reproduction, life expectancy at birth, net reproductive rates, generation time, life span, the intrinsic rate of population increase, and finite rate of increase. In the present study, the effects of DDT and dicofol on survival and reproduction of the rotifer Brachionus calyciflorus were investigated using life table demography. The results showed that treatments with $0.32-1.28 \mathrm{mg} / \mathrm{L}$ DDT and $0.64-1.28 \mathrm{mg} / \mathrm{L}$ dicofol significantly declined the agespecific survivorship of rotifers. Treatments with 0.32 and $0.64 \mathrm{mg} / \mathrm{L}$ DDT and $0.32-1.28 \mathrm{mg} / \mathrm{L}$ dicofol significantly prolonged the juvenile period of rotifers. Treatment with $0.08 \mathrm{mg} / \mathrm{L}$ DDT significantly prolonged survival time of rotifers. All tested life table variables of rotifers, except generation time, were significantly influenced by DDT and dicofol at concentrations of 0.08-1.28 mg/L. In addition, DDT revealed far greater negative impacts on life table demographic variables of rotifers in comparison to dicofol.
\end{abstract}

Keywords: DDT, dicofol, toxicity, Brachionus calyciflorus, life table demography

\section{Introduction}

Dichlorodiphenyltrichloroethanes

(DDTs) are effective pesticides and have been widely used to control

*e-mail: xuxp1979@126.com agricultural, animal and human insect diseases since the Second World War. In China, the total production of DDTs reached 270,000 tons from 1960 to 1980 [1]. DDTs are typical persistent organic pollutants (POPs). Due to their chronic toxicity, environmental persistence, and bioaccumulative abilities, DDTs have raised great environmental concerns in past decades [2]. Although 
DDTs have been banned in China since 1983, their residues are still persisting in environments and will influence organisms for a long time [3].

As a substitute for DDTs, dicofol was invented as an acaricide to prevent mites on cotton, fruit, and flowers. Dicofol is synthesized from $\mathrm{C}_{6} \mathrm{H}_{5} \mathrm{Cl}$ and $\mathrm{CCl}_{3} \mathrm{CHO}$, with DDTs as the intermediates. Recent surveys have revealed new DDT inputs (i.e., "dicofol-type" DDT input pattern) at some waterbodies in China, which was speculated to originate from current production and the wide application of dicofol [4-6], since dicofol products inevitably contain DDT-related compounds as impurities [1].

Both DDTs and dicofol can enter the aquatic environment in agricultural runoff of rain and irrigation, where they pose significant toxicological risks to resident organisms. Toxicity assessments of DDTs and dicofol have been conducted on various organisms, including humans, mammals, fish, birds, Daphnia and copepods. The results showed that these organochlorine pesticides adversely affected organisms even at low concentrations [7-10]. Therefore, to comprehensively understand environmental risks of DDTs and dicofol, toxicity assessments should be investigated on as many species as possible, especially those abundant, widely distributed, and ecologically important organisms.

Rotifers are widespread and generally abundant in aquatic ecosystems and play significant roles in aquatic ecosystems [11-12]. Rotifers are also valuable live feeds for aquaculture and fisheries [13]. Due to the easy culture process and high sensitivity to pollutants, rotifers in the genus Brachionus are promising model animals for toxicity assessments. From 2004, the monogonont rotifer B. calyciflorus has been included as a standard freshwater bioassay species by the American Society for Testing and Materials [14]. Thereafter, toxicity evaluations using Brachionus have been successfully applied to heavy metals, pesticides, and other chemical compounds [15-19]. Because of their wide distribution and inevitable contact in aquatic ecosystems, it is necessary to assess the effects of DDT and dicofol on Brachionus rotifers.

Regarding the effects of DDT and dicofol on rotifers, Rao and Sarma [20] first reported the effects of sublethal concentrations of DDT on the demographic parameters of $B$. patulus. Thereafter, Xi et al. [21] investigated the toxicities of DDT and dicofol to the sexual reproduction of $B$. calyciflorus by 3-day population growth tests, and $\mathrm{Xu}$ et al. [22] evaluated the long exposure effects of DDT and dicofol on population growth of B. calyciflorus under different algal densities. Life table demography is an important tool for measuring the chronic effects of toxicants on R-strategist species, and the life table parameters of rotifers suggests the suitable and sensitive endpoints for assessing the toxicity of chemicals [12]. Until now, responses of life table demographic variables of $B$. calyciflorus to DDT and dicofol - such as age at first reproduction, life expectancy at birth, net reproductive rates, generation time, life span, and the intrinsic rate of population increase and finite rate of increase - have not been reported.

Based on single species toxicity experiments, safe concentrations of chemicals could be calculated and extrapolated to population, community, and ecosystem effects [23]. In the present study, to comprehensively reveal toxicity of DDT and dicofol to rotifers, changes of life table demographic parameters of $B$. calyciflorus in response to DDT dicofol exposure were investigated. These results would contribute knowledge of environmental risk of DDT and dicofol to aquatic ecosystems.

\section{Materials and Methods}

\section{Chemicals and Preparation of Testing Solutions}

DDT (2,4'-Dichlorodiphenyltrichloroethane, CAS: 789-02-6, $\mathrm{C}_{14} \mathrm{H}_{9} \mathrm{Cl}_{5}$, purity $>99 \%$ ) and dicofol (CAS:115$32-2, \mathrm{C}_{14} \mathrm{H}_{9} \mathrm{Cl}_{5} \mathrm{O}$, purity $>99 \%$ ) were purchased from Sigma-Aldrich (Munich, Germany) and then dissolved in acetone to prepare $10 \mathrm{mg} / \mathrm{L}$ stock solutions. The stock solutions were stored at $4^{\circ} \mathrm{C}$.

Based on results of pre-tests, five concentrations $(0.08,0.16,0.32,0.64$, and $1.28 \mathrm{mg} / \mathrm{L})$ of DDT and dicofol were included. These testing solutions were prepared by diluting stock solution with EPA medium [24] with final acetone concentrations of lower than $0.2 \%(\mathrm{v} / \mathrm{v})$. Blank control using the EPA medium and solvent control $(0.2 \%$ acetone in EPA, $v / v)$ were also performed. The actual concentrations of DDT and dicofol were determined using an Agilent 6890 gas chromatograph (Wilmington, DE, USA) equipped with an ${ }^{63} \mathrm{Ni}$ electron capture detector $(\mu$-ECD) and a fused silica capillary column (DB-5, $30 \times 0.25 \mathrm{~mm}$ i.d. and $0.25 \mu \mathrm{m}$ film thickness). Nitrogen was used as the carrier and makeup gas [25].

\section{Culture of Animals}

B. calyciflorus was originally isolated from Lake Jinghu $\left(31^{\circ} 33^{\prime} \mathrm{N}, 118^{\circ} 37^{\prime} \mathrm{E}\right.$, Wuhu, China), and then clonally cultured in the hard synthetic freshwater at $25 \pm 1^{\circ} \mathrm{C}$. The light cycle was $12: 12 \mathrm{~h}$ (light:dark) with light intensity of 3000 lux. After six months, rotifers were transferred daily to new medium containing and fed fresh green algae Scenedesmus obliquus at a density of $3.0 \times 10^{6}$ cells $/ \mathrm{mL} S$. obliquus were grown in a semi-continuous culture using HB-4 medium [24]. Algae at exponential growth phase were harvested by centrifugation at $4,000 \mathrm{rpm}$ and counted using a hemacytometer under a microscope.

\section{Life Table Experiments}

Before commencement of experiments, rotifers with amictic eggs were transferred to a glass dish and placed under the same conditions. Within $2 \mathrm{~h}$, newly born 
rotifers were collected for life table experiments, which were carried out in 24-well tissue culture plates. Each well contained one neonate $(<2 \mathrm{~h}$ old $)$ and $0.5 \mathrm{~mL}$ of test solution with $3.0 \times 10^{6}$ cells $/ \mathrm{mL} S$. obliquus. Rotifers were observed every $2 \mathrm{~h}$ during the initial $48 \mathrm{~h}$, and the time at production of the first egg and at hatching of the first neonate was recorded. Next, the number of produced eggs and hatched neonates, the number of original individuals alive were recorded every $8 \mathrm{~h}$ and then neonates were discarded. Testing solutions were changed every $24 \mathrm{~h}$. The life table experiments were conducted in darkness (excepting when the rotifers were observed under a light microscope) at $25 \pm 1^{\circ} \mathrm{C}$ until all individuals died. Each treatment was repeated 40 times. Data of each ten replicates were pooled randomly to calculate life table parameters.

Based on the as-obtained data, duration of juvenile period, survival time of every individual, age-specific survivorship $\left(l_{\mathrm{x}}, \mathrm{x}\right.$ was defined as the age interval) and age-specific fecundity $\left(m_{\mathrm{x}}\right)$ were calculated as described previously [26]. Net reproductive rate $\left(R_{0}\right)$, generation time $(T)$, life expectancy at hatching $\left(e_{0}\right)$, intrinsic rate of population increase $\left(r_{\mathrm{m}}\right)$, and finite rate of increase $(\lambda)$ were calculated according to Sha et al. [17].

\section{Statistical Analysis}

All the data analyses were carried out using the SPSS package 16.0 (SPSS, Inc.). One-way analysis of variance (ANOVA) was conducted to identify significant differences in each life-table demographic parameter among treatments, followed by pair-wise comparisons using least significant difference (LSD) post-hoc tests [27]. $p<0.05$ was considered statistically significant.

\section{Results and Discussion}

Life table experiments derive both survivorshipand reproduction-related variables, which are sensitive indicators to environmental stresses [28]. Among them, age at first reproduction, life expectancy at birth, net reproductive rates, generation time, and the intrinsic rate of population increase of rotifers have been quantified to represent environmental disturbances and toxic stressors $[12,29]$. In the present study, all tested life table variables (except generation time) were all significantly influenced by treatments with $0.08-1.28 \mathrm{mg} / \mathrm{L}$ DDT and dicofol (Table 1), suggesting that life table demography was a suitable method to assess chronic effects of DDT and dicofol on B. calyciflorus.

\section{DDT and Dicofol Prolonged Juvenile Period and Survival Time}

Compared with the blank control, treatment with $0.2 \%$ acetone did not affect juvenile period and survival time of B. calyciflorus ( $p>0.05$, Fig. 1). However, treatments with 0.32 and $0.64 \mathrm{mg} / \mathrm{L}$ DDT
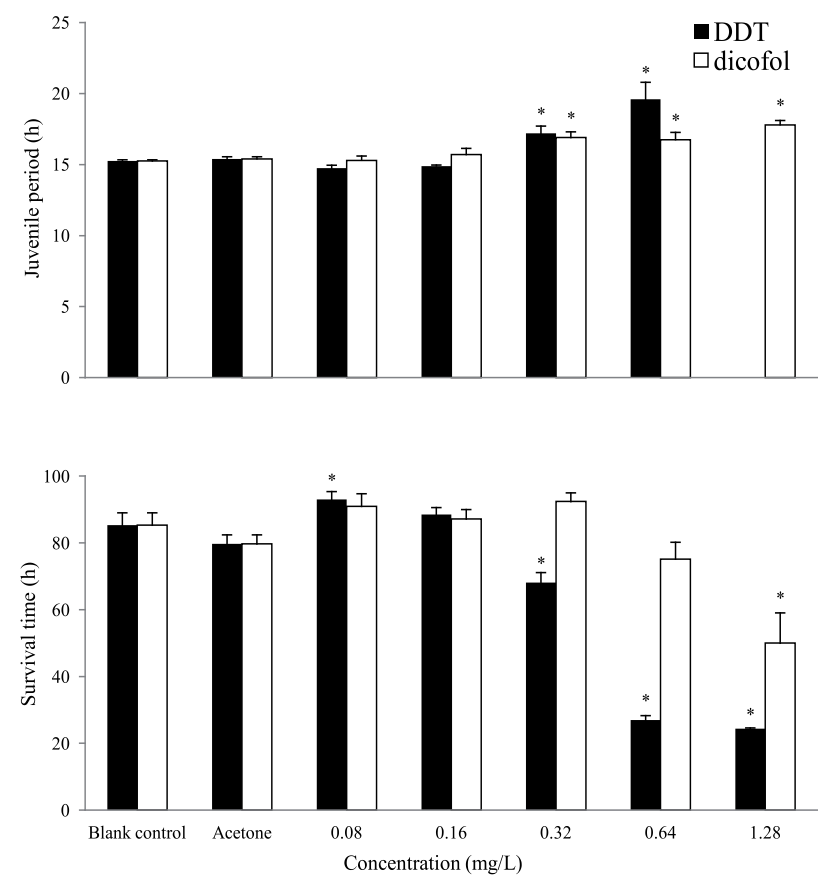

Fig. 1. Durations of juvenile period and survival time of Brachionus calyciflorus exposed to different concentrations of DDT and dicofol; * Significant $(p<0.05)$ difference from the blank controls.

and $0.32-1.28 \mathrm{mg} / \mathrm{L}$ dicofol significantly prolonged the juvenile period $(p<0.05)$. Treatment with $0.08 \mathrm{mg} / \mathrm{L}$ DDT significantly prolonged survival time $(p<0.05)$. Treatments with $0.32-1.28 \mathrm{mg} / \mathrm{L}$ DDT and $1.28 \mathrm{mg} / \mathrm{L}$ dicofol significantly shortened survival time $(p<0.05)$. Elongation of juvenile period and the decrease of survival time should reduce population growth of rotifers [30].

\section{DDT and Dicofol Affected Both Survivorship and Fecundity of Rotifers}

Survivorship parameters are generally less sensitive to stress than reproduction parameters [28]. For example, survivorship of $B$. rubens was not affected by treatments with low levels of DDT, while net reproductive rate and intrinsic rate of increase were depressed significantly [20]. In the present study, treatment with $0.32,0.64$ and $1.28 \mathrm{mg} / \mathrm{L}$ DDT significantly declined age-specific survivorship $\left(l_{\mathrm{x}}\right)$ after 16,16 and $40 \mathrm{~h}$, respectively, in comparison to the control. Similarly, there were significant declines of $l_{\mathrm{x}}$ in treatments with 0.64 and $1.28 \mathrm{mg} / \mathrm{L}$ dicofol after $16^{\mathrm{x}} \mathrm{h}$ (Figs 2, 3). These results suggested that both survival time and rate were sensitive to DDT and dicofol at tested concentrations.

Results of age-specific fecundity $\left(m_{\mathrm{x}}\right)$ also revealed negative effects of DDT and dicofol on rotifer reproduction (Figs 2, 3). Compared to the controls, treatment with $0.32 \mathrm{mg} / \mathrm{L}$ DDT significantly decreased $m_{\mathrm{x}}$ during $16 \mathrm{~h}$ to $72 \mathrm{~h}$, and treatments with 0.64 and $1.28 \mathrm{mg} / \mathrm{L}$ DDT displayed the most severe inhibition 
of reproduction during the exposure time. In response to treatments with 0.64 and $1.28 \mathrm{mg} / \mathrm{L}$ dicofol,
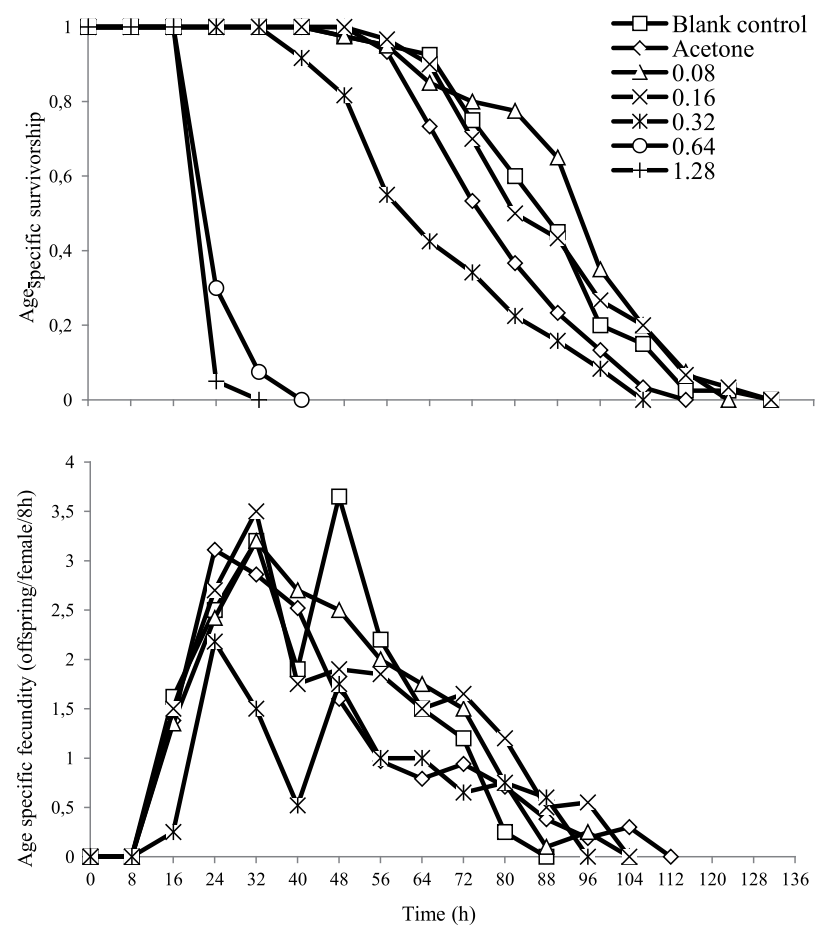

Fig. 2. Age-specific survivorship $\left(l_{x}\right)$ and fecundity $\left(m_{x}\right)$ of Brachionus calyciflorus exposed to different concentrations (mg/L) of DDT.
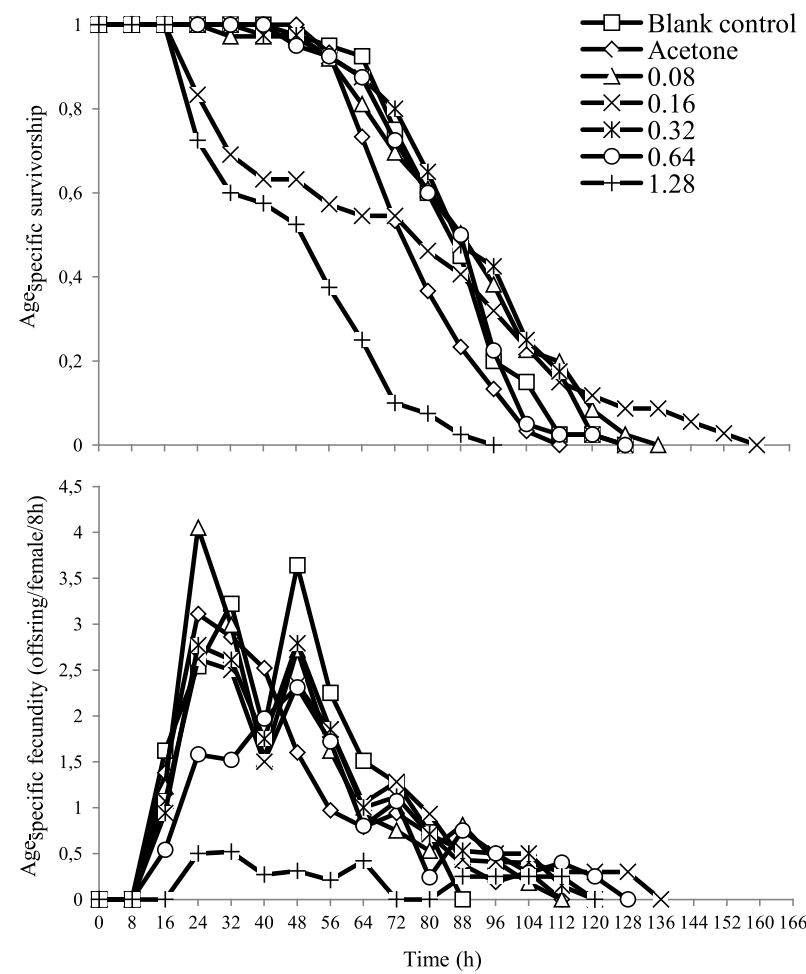

Fig. 3. Age-specific survivorship $\left(l_{x}\right)$ and fecundity $\left(m_{x}\right)$ of Brachionus calyciflorus exposed to different concentrations $(\mathrm{mg} / \mathrm{L})$ of dicofol. the age-specific fecundity $\left(m_{\mathrm{x}}\right)$ significantly decreased from $16 \mathrm{~h}$ to $80 \mathrm{~h}$ (Figs 2, 3).

\section{Effects of DDT and Dicofol on Life Table Demographic Parameters}

Compared with the blank control, treatment with acetone $(0.2 \%, \mathrm{v} / \mathrm{v})$ did not affect life-table demographic parameters $(p>0.05)$, suggesting that solvents in testing solutions did not disturb the effects of DDT and dicofol (Table 1).

Several studies have found that sublethal concentrations of dieldrin, polyfluorinated compounds, and rifampicin significantly prolonged $T$ of $B$. calyciflorus [23, 26, 31], while thiophanate-methyl, polybrominated diphenyl ethers (BDE-47), and mercury significantly shortened $T$ of rotifers [17, 30, 32]. In the present study, no significant change of $T$ was detected in all treatments $(p>0.05)$, similar to Rao and Sarma [20]. These results suggested that $T$ might be insensitive to DDT and dicofol - probably attributed to the physical and biochemical properties of chemicals and the anatomy and physiology of test animals [17]. In comparison, when exposed to $0.32 \mathrm{mg} / \mathrm{L}$ DDT and 0.64 and $1.28 \mathrm{mg} / \mathrm{L}$ dicofol, $R_{0}, r_{\mathrm{m}}$, and $\lambda$ decreased significantly $(p<0.05)$. Treatments with $0.32 \mathrm{mg} / \mathrm{L}$ DDT and $1.28 \mathrm{mg} / \mathrm{L}$ dicofol significantly decreased $e_{0}(p<0.05)$. It is worth noting that $B$. calyciflorus exposed to 0.64 and $1.28 \mathrm{mg} / \mathrm{L}$ DDT could not survive the reproductive period, which contributed to the null values in these treatments (Table 1). The present results suggested that $R_{0}, r_{\mathrm{m}}$, and $\lambda$ could be used to monitor DDT pollution and $e_{0}$ could be used to assess the toxicity of dicofol.

\section{DDT Displayed Potential Endocrine Disruption Activity}

Organochlorine pesticides such as chlordecone, aldrin, and dieldrin generally display endocrinedisrupting activity (lengthened reproductive period) at low concentrations, but reveal toxicity at high concentrations [26]. For example, treatment with $0.05 \mathrm{mg} / \mathrm{L}$ chlordecone and 0.02-0.16 mg/L aldrin prolonged the life span of $B$. calyciflorus, and $0.001-1000 \mu \mathrm{g} / \mathrm{L}$ dieldrin elongated generation time and life expectancy of rotifers. In the present study, survival time significantly increased in treatment with $0.08 \mathrm{mg} / \mathrm{L}$ DDT, but decreased at concentrations higher than $0.32 \mathrm{mg} / \mathrm{L}$, displaying typical characteristics of hormesis that low concentration stimulate but high concentration inhibit [33]. Moreover, hormesis were observed more often in reproduction endpoints than survival [17, 34]. However, in the present study, reproductive parameters were not affected by treatment with $0.08 \mathrm{mg} / \mathrm{L}$ DDT, suggesting that low concentrations of DDT could cause obvious hormesis on survival rather than reproduction indices. These results stated that the hormesis effects on reproduction and lifespan of rotifers varied among toxicants and concentrations. 
Table 1. Net reproductive rate $\left(R_{0}\right)$, generation time $(T)$, life expectancy at hatching $\left(e_{0}\right)$, intrinsic rate of population increase $\left(r_{\mathrm{m}}\right)$, and finite rate of increase of Brachionus calyciflorus exposed to different concentrations of DDT and dicofol.

\begin{tabular}{|c|c|c|c|c|c|c|}
\hline Toxicant & Concentration $(\mathrm{mg} / \mathrm{L})$ & $R_{0}(\mathrm{ind})$ & $T(\mathrm{~h})$ & $e_{0}(\mathrm{~h})$ & $r_{\mathrm{m}}(/ \mathrm{d})$ & $\lambda(/ \mathrm{d})$ \\
\hline Blank control & EPA medium & $17.10 \pm 1.55$ & $41.00 \pm 1.57$ & $81.33 \pm 3.70$ & $0.0887 \pm 0.0012)$ & $1.0927 \pm 0.0013$ \\
\hline Acetone & $0.2 \%(\mathrm{v} / \mathrm{v})$ & $13.8 \pm 0.69$ & $38.46 \pm 2.19$ & $75.73 \pm 2.71$ & $0.0864 \pm 0.0015$ & $1.0902 \pm 0.0017$ \\
\hline DDT & 0.08 & $17.55 \pm 0.81$ & $43.34 \pm 0.79$ & $89.00 \pm 2.41$ & $0.0858 \pm 0.0010$ & $1.0900 \pm 0.0010$ \\
\hline & 0.16 & $16.50 \pm 0.38$ & $42.51 \pm 0.57$ & $84.53 \pm 2.08$ & $0.0882 \pm 0.0020$ & $1.0922 \pm 0.0021$ \\
\hline & 0.32 & $7.42^{*} \pm 1.39$ & $38.77 \pm 1.10$ & $64.13^{*} \pm 3.01$ & $0.0596^{*} \pm 0.0056$ & $1.0615^{*} \pm 0.0059$ \\
\hline & 0.64 & - & - & - & - & - \\
\hline & 1.28 & - & - & - & - & - \\
\hline & 0.08 & $15.93 \pm 1.79$ & $40.34 \pm 0.31$ & $86.97 \pm 3.79$ & $0.0893 \pm 0.0052$ & $1.0934 \pm 0.0056$ \\
\hline & 0.16 & $14.20 \pm 1.16$ & $42.22 \pm 1.42$ & $83.20 \pm 2.83$ & $0.0811 \pm 0.0016$ & $1.0845 \pm 0.0017$ \\
\hline & 0.32 & $14.30 \pm 0.78$ & $43.90 \pm 1.31$ & $88.40 \pm 2.62$ & $0.0794 \pm 0.0035$ & $1.0827 \pm 0.0038$ \\
\hline & 0.64 & $8.34^{*} \pm 0.63$ & $45.89 \pm 2.44$ & $71.17 \pm 5.06$ & $0.0583^{*} \pm 0.0017$ & $1.0600^{*} \pm 0.0018$ \\
\hline & 1.28 & $0.95^{*} \pm 0.31$ & $36.15 \pm 3.71$ & $46.00^{*} \pm 9.08$ & $-0.0077^{*} \pm 0.0127$ & $0.9926^{*} \pm 0.0125$ \\
\hline
\end{tabular}

*Significant $(p<0.05)$ difference from the blank controls.

\section{Trade-off Between Survival and Reproduction}

There is a trade-off between longevity and reproductive performance in rotifers. Under pesticide stresses, Philodina roseola allocating more energy to reproduction, which would negatively affect future reproductive performance of offspring and its own survival [35]. Sun et al. [36] also reported that the trade-off between lifespan and reproduction at different food conditions in B. plicatilis. To the best of our knowledge, no report has investigated the possible trade-off between reproduction and lifespan in rotifers when exposed to sublethal DDT and dicofol. In the present study, $B$. calyciflorus exposed to $0.64 \mathrm{mg} / \mathrm{L}$ DDT could successfully finish the juvenile period and produce eggs. However, partial eggs soon detached from female rotifers before hatching, indicating that rotifers preferred to invest more energy to survival rather than reproduction, which supported the hypothesis that the trade-off between survival and reproduction generally occurs when rotifers confront stressful environments [37]. Moreover, this trade-off became more obvious when increasing concentrations of DDT, since the inhibition of reproduction was more severe in treatments with high than low DDT levels, with a clear dose-response relationship between $R_{0}, e_{0}, r_{\mathrm{m}}, \lambda$ and concentrations of DDT and dicofol (Table 2).

\section{Comparison of Toxicity Between DDT and Dicofol}

To better compare toxicity of DDT and dicofol, the same series of concentrations were used for these two pesticides. Although their structures were

Table 2. Relationships between net reproductive rate $\left(R_{0}\right)$, life expectancy at hatching $\left(e_{0}\right)$, intrinsic rate of population increase $\left(r_{\mathrm{m}}\right)$, and finite rate of increase of Brachionus calyciflorus and concentrations (x, mg/L) of DDT and dicofol.

\begin{tabular}{|c|c|c|c|}
\hline Toxicant & Parameter & Regression equation & Significant test \\
\hline DDT & $R_{0}$ (ind.) & $\mathrm{y}=-160.53 \mathrm{x}^{2}+21.4395 \mathrm{x}+17.0207$ & $\mathrm{r}^{2}=0.862, p<0.01$ \\
\hline & $e_{0}(\mathrm{~h})$ & $\mathrm{y}=-512.74 \mathrm{x}^{2}+107.012 \mathrm{x}+82.1291$ & $\mathrm{r}^{2}=0.817, p<0.01$ \\
\hline & $r_{\mathrm{m}}(/ \mathrm{d})$ & $\mathrm{y}=-0.4478 \mathrm{x}^{2}+0.0591 \mathrm{x}+0.0871$ & $\mathrm{r}^{2}=0.849, p<0.01$ \\
\hline & $\lambda$ & $\mathrm{y}=-0.481 \mathrm{x}^{2}+0.063 \mathrm{x}+1.091$ & $\mathrm{r}^{2}=0.850, p<0.01$ \\
\hline & $R_{0}($ ind. $)$ & $\mathrm{y}=-0.0776 \mathrm{x}^{2}-12.503 \mathrm{x}+16.9949$ & $\mathrm{r}^{2}=0.883, p<0.01$ \\
\hline & $e_{0}(\mathrm{~h})$ & $\mathrm{y}=-24.575 \mathrm{x}^{2}+0.3445 \mathrm{x}+85.1334$ & $\mathrm{r}^{2}=0.707, p<0.01$ \\
\hline & $r_{\mathrm{m}}(/ \mathrm{d})$ & $\mathrm{y}=-0.0433 \mathrm{x}^{2}-0.0200 \mathrm{x}+0.0889$ & $\mathrm{r}^{2}=0.914, p<0.01$ \\
\hline & $\lambda$ & $\mathrm{y}=-0.042 \mathrm{x}^{2}-0.024 \mathrm{x}+1.093$ & $\mathrm{r}^{2}=0.918, p<0.01$ \\
\hline
\end{tabular}


Table 3. Estimates of chronic toxicity of DDT and dicofol on the net reproductive rate $\left(R_{0}\right)$, life expectancy at hatching $\left(e_{0}\right)$, intrinsic rate of population increase $\left(r_{\mathrm{m}}\right)$, and finite rate of increase of Brachionus calyciflorus.

\begin{tabular}{|c|c|c|c|c|}
\hline Toxicant & Parameter & NOEC $(\mathrm{mg} / \mathrm{L})$ & LOEC $(\mathrm{mg} / \mathrm{L})$ & EC50 (mg/L) \\
\hline DDT & $R_{0}$ (ind.) & 0.16 & 0.32 & 0.30 \\
\hline & $e_{0}(\mathrm{~h})$ & 0.16 & 0.32 & 0.40 \\
\hline & $\left.r_{\mathrm{m}} / \mathrm{d}\right)$ & 0.16 & 0.32 & 0.38 \\
\hline & $\lambda$ & 0.16 & 0.32 & 1.13 \\
\hline Dicofol & $R_{0}($ ind.) & 0.32 & 1.28 & 1.32 \\
\hline & $e_{0}(\mathrm{~h})$ & 0.64 & 0.64 & 0.80 \\
\hline
\end{tabular}

NOEC: no-observed effect concentration; LOEC: lowest-observed-effect concentration; EC50: median effective concentration

similar, DDT and dicofol showed different toxicity to B. calyciflorus. Comparisons of NOEC (no-observed effect concentration), LOEC (lowest-observedeffect concentration) and EC50 (median effective concentrations) values on each parameter showed that all these values for DDT were lower than those for dicofol (Table 3), suggesting that most life table parameters of $B$. calyciflorus were more sensitive to DDT than dicofol, and that DDT was more toxic to $B$. calyciflorus than dicofol. These results agreed with the published results associating changes of sexual reproduction and longterm population growth of $B$. calyciflorus in response to treatments with DDT and dicofol [21-22].

\section{Conclusions}

In summary, the results of the present study showed that both DDT and dicofol had adverse effects on $B$. calyciflorus. The life table variables of rotifers (except generation time) were all significantly influenced by both DDT and dicofol at $0.08-1.28 \mathrm{mg} / \mathrm{L}$, and were suitable endpoints for assessing the effect of the DDT and dicofol on survival and reproduction of the rotifers. The phenomena of hormesis and trade-off between survival and reproduction have been found when B. calyciflorus were exposed to DDT at 0.08 and $0.64 \mathrm{mg} / \mathrm{L}$, respectively. Compared with dicofol, DDT was more toxic to life table demographic variables of rotifers.

\section{Acknowledgements}

This work was supported by the National Natural Science Foundation of China (51978001, 51878004), the Anhui Province Natural Science Foundation (1808085ME133), the Excellent Youth Talent Support Project of High Education of Anhui Province (gxyq2018023), the Project Funding for
Young and Middle-aged Top Talents of Anhui Polytechnic University (2017).

\section{Conflict of Interest}

The authors declare no conflict of interest.

\section{References}

1. QIU X.H., ZHU T., YAO B., HU J.X., HU S.W. Contribution of dicofol to the current DDT pollution in China. Environ. Sci. Technol. 39, 4385, 2005.

2. LI S.M., TIAN Y.J., DING Q., LIU W.B. The release of persistent organic pollutants from a closed system dicofol production process. Chemosphere. 94, 164, 2014.

3. GUO G.H., WU F.C., HE H.P., FENG C.L., LI H.X., ZHANG R.Q., ZHAO X.L., LIAO H.Q. Preliminary ecological risk assessment of DDT in surface waters of China. Acta. Sci. Circumstantiae. 31, 2545, 2011.

4. ZHOU S.S., YANG H.Y., ZHANG A.P., LI Y.F., LIU W.P. Distribution of organochlorine pesticide in sediments from Yangtze River Estuary and the adjacent East China Sea: implication of transport, sources and trends. Chemosphere. 114, 26, 2014.

5. ZHENG S., CHEN B., QIU X., CHEN M., MA Z., YU $X$. Distribution and risk assessment of 82 pesticides in Jiulong River and estuary in South China. Chemosphere. 144, 1177, 2016.

6. LI W.D., YANG H.Y., XIA J., LIU Q., SUN Y., ZHOU J.Z. Residues and distribution of organochlorine pesticides in water and suspended particulate matter from Hangzhou Bay, East China Sea. Bull. Environ. Contam. Toxicol. 96, 295, 2016.

7. JAYARAJ R., MEGHA P., SREEDEV P. Organochlorine pesticides, their toxic effects on living organisms and their fate in the environment. Interdiscipl Toxicol. 9, 90, 2016.

8. CHOPRA A.K., SHARMA M.K., CHAMOLI S. Bioaccumulation of organochlorine pesticides in aquatic system-an overview. Environ. Monit. Assess. 173, 905, 2011.

9. WANG X., WANG W.X. Uptake, absorption efficiency and elimination of DDT in marine phytoplankton, copepods and fish. Environ. Pollut. 136, 453, 2005. 
10. BETTINETTI R., CROCE V., NOÈ F., PONTI B., QUADRONI S., GALASSI S. Ecotoxicity of pp'DDE to Daphnia magna. Ecotoxicology. 22, 1255, 2013.

11. DIAS J.D., BONECKER C.C., MIRACLE M.R. The rotifer community and its functional role in lakes of a neotropical floodplain. Int. Rev. Hydrobiol. 99, 72, 2014.

12. DAHMS H.U., HAGIWARA A., LEE J.S. Ecotoxicology, ecophysiology, and mechanistic studies with rotifers. Aquat. Toxicol. 101, 1, 2011.

13. WON E.J., HAN J., KIM D.H., DAHMS H.U., LEE J.S. Rotifers in ecotoxicology. In: Rotifers: aquaculture, ecology, gerontology, and ecotoxicology, Hagiwara A., Yoshinaga T, Springer, Tokyo, 2017.

14. ASTM. American Society for Testing and Materials. Standard guide for acute toxicity test with the rotifer Brachionus. PA, USA, E1440, 2004.

15. COPPER C.A., TAIT T., GRAY H., CIMPRICH G., SANTORE R.C., MCGEER J.C., WOOD C.M., SMITH D.S. Influence of salinity and dissolved organic carbon on acute $\mathrm{Cu}$ toxicity to the rotifer Brachionus plicatilis. Environ. Sci. Technol. 48, 1213, 2013.

16. GUO R., CHEN J. Assessing the impacts of dimethoate on rotifers' reproduction through the pre-exposure history. Ecotoxicol. Environ. Saf. 111, 199, 2015.

17. SHA J.J., YOU W., CHEN H.M., WANG M., WANG H., LI X.H., QI L., TANG X.X. Using population demographic parameters to assess impacts of two polybrominated diphenyl ethers (BDE-47, BDE-209) on the rotifer Brachionus plicatilis. Ecotoxicol. Environ. Saf. 119, 106, 2015.

18. ZHANG L.L., NIU J.F., WANG Y.J. Full life-cycle toxicity assessment on triclosan using rotifer Brachionus calyciflorus. Ecotoxicol. Environ. Saf. 127, 30, 2016.

19. JIN S.C., SHAO L., SONG X.P., XIAO J.H., OUYANG K., ZHANG K.L., YANG J.X. Fertilization and male fertility in the rotifer Brachionus calyciflorus in the presence of three environmental endocrines. Chemosphere. 220, 146, 2019.

20. RAO T.R., SARMA S.S.S. Demographic parameters of Brachionus patulus Müller (Rotifera) exposed to sublethal DDT concentrations at low and high food levels. Hydrobiologia. 139, 193, 1986.

21. XI Y.L., CHU Z.X., XU X.P. Effect of four organochlorine pesticides on the reproduction of freshwater rotifer Brachionus calyciflorus Pallas. Environ. Toxicol. Chem. 26, 1695, 2007.

22. XU X.P., XI Y.L., CHU Z.X., XIANG X.L. Effects of DDT and dicofol on population growth of Brachionus calyciflorus Pallas (Rotifera) under different algal (Scenedesmus obliquus) densities. J. Environ Biol. 35, 907, 2014.

23. ZHANG L.L., NIU J.F., LI Y., WANG Y.J., SUN D. Evaluating the sub-lethal toxicity of PFOS and PFOA using rotifer Brachionus calyciflorus. Environ. Pollut. 180, 34, 2013.

24. XU X.P., XI Y.L., LI J.Y. Effects of deltamethrin and endosulfan on the population growth of Brachionus calyciflorus at different algal (Scenedesmus obliquus) densities. Pol. J. Environ. Stud. 28, 407, 2019.

25. KONG W.J., LIU Q.T., KONG D.D., LIU Q.Z., MA X.P., YANG M.H. Trace analysis of multi-class pesticide residues in Chinese medicinal health wines using gas chromatography with electron capture detection. Sci. Rep. 6, 21558, 2016.

26. HUANG L., XI Y.L., ZHA C.W., ZHAO L.L., WEN X.L. Effects of dieldrin and 17ß-estradiol on life history characteristics of freshwater rotifer Brachionus calyciflorus Pallas. J. Freshwater Ecol. J. Freshwater Ecol. 27, 381, 2012.

27. ZAR J.H. Biostatistical Analysis (5th Edition). PrenticeHall, Inc. 2007.

28. KAMMENGA J., LASKOWSKI R. Demographic approaches in ecotoxicology-Open problems. BMC Struct. Biol. 12, 1, 2000.

29. GONZÁLEZ-PÉREZ B.K., SARMA S.S.S., NANDINI S. Effects of selected pharmaceuticals (ibuprofen and amoxicillin) on the demography of Brachionus calyciflorus and Brachionus havanaensis (Rotifera). Egypt. J. Aquat. Res. 42, 341, 2016.

30. XI Y.L., HU H.Y. Effect of thiophanate-methyl on the reproduction and survival of the freshwater rotifer Brachionus calyciflorus Pallas. Bull. Environ. Contam. Toxicol. 71, 0722, 2003.

31. ZHAI P., WEN X.L., CHEN Z.W., ZHAO Z., LI H.Y., XI Y.L. Effects of rifampicin on life table demography of Brachionus calyciflorus under different Scenedesmus obliquus densities. China Environ. Sci. 36, 1886, 2016.

32. REBOLLEDO U.A., NANDINI S., SÁNCHEZ O.E., SARMA S.S.S. Combined effects of temperature and salinity on the demographic response of, Proales similis, (Beauchamp, 1907) and, Brachionus plicatilis, (Müller, 1786) (Rotifera) to mercury. Chemosphere. 202, $312,2018$.

33. FORBES V.E. Is hormesis an evolutionary expectation? Funct. Ecol. 14, 12, 2000.

34. DHAWAN R., DUSENBERY D.B., WILLIAMS P.L. Comparison of lethality, reproduction, and behavior as toxicological endpoints in the nematode Caenorhabditis elegans. J. Environ. Sci. Health. Part A. 58, 451, 1999.

35. MOREIRA R.A., ADRISLAINE D.S.M., ROCHA O. The toxicity of carbofuran to the freshwater rotifer, Philodina roseola. Ecotoxicology. 24, 604, 2015.

36. SUN Y.F., HOU X.Y., XUE X.F., ZHANG L., ZHU X.X., HUANG Y., CHEN Y.F., YANG Z. Trade-off between reproduction and lifespan of the rotifer Brachionus plicatilis under different food conditions. Sci. Rep. 7, 15370, 2017.

37. BOUCHNAK R., STEINBERG C.E.W. Algal diets and natural xenobiotics impact energy allocation in cladocerans. I. Daphnia magna. Limnologica. 43, 434, 2013. 
